\title{
The War on Illegal Drugs in Producer and Consumer Countries: A Simple Analytical Framework
}

\author{
DANIEL MEJÍA
}

CESIFO WORKING PAPER No. 2459

CATEgory 2: Public ChOICE

NOVEMBER 2008

Presented At CESifo Venice SuMmer Institute 2008, Workshop ON

'Illicit Trade AND GlobalisAtion'

\footnotetext{
An electronic version of the paper may be downloaded

- from the SSRN website: www.SSRN.com

- from the RePEc website: - from the CESifo website: 


\title{
The War on Illegal Drugs in Producer and Consumer Countries: A Simple Analytical Framework
}

\begin{abstract}
This paper develops a model of the war against illegal drugs in both producer and consumer countries. The paper studies the trade-off faced by the government of the drug consumer country between prevention policies (aimed at reducing the demand for drugs) and enforcement policies (aimed at reducing the production and trafficking of drugs), and shows how the optimal allocation of resources between these two alternatives depends on the key parameters of the model. We use available data for the war on drugs in Colombia, and against consumption in the U.S., to calibrate the unobservable parameters of the model, such as the price elasticity of demand for cocaine; the effectiveness of prevention and treatment policies; and the relative effectiveness of interdiction efforts.
\end{abstract}

JEL Code: D74, K42.

Keywords: war on drugs, conflict, enforcement, prevention and treatment policies, Plan Colombia.

\author{
Daniel Mejía \\ Fedesarrollo and Department of Economics \\ Universidad de los Andes \\ Carrera 1 No $18 \mathrm{~A}$ \\ 70 Bloque C Piso 3 Oficina 310A \\ Colombia - Bogotá \\ dmejia@uniandes.edu.co
}

October 2008

Paper presented at CESifo workshop on Illicit Trade and Globalisation, Venice, July 2008. The author wishes to thank Rosalie Liccardo Pacula, as well as workshop participants, for stimulating comments. Alejandro Ordoñez and Nicolas Idrobo provided excellent research assistance. Financial support from Fedesarrollo's "German Botero de los Ríos" 2008 Prize for Economic Research and the Open Society Institute is greatly acknowledged. 


\section{Introduction}

During the last decade, there has been a drastic intensification of the war against cocaine production and trafficking, not only in Latin-American producer countries but, also, in some of the main consumer countries such as the United States. For instance, in Colombia, where about $70 \%$ of the cocaine consumed in the world is produced, during the last 7 years the U.S. and the Colombian governments have allocated huge amounts of resources to combat production and trafficking under the so-called Plan Colombia. ${ }^{1}$ According to the Colombian National Planning Department (DNP, 2006), between 2000 and 200, the U.S. government has spent about $\$ 3.8$ billion dollars in subsidies to the Colombian government for its war against illegal drug producers and traffickers. Colombia for its part has spent about $\$ 6.9$ billion during the same period. About half of the Colombian expenses (about $\$ 3.4$ billion) and about three-quarters of the U.S. subsidies (about $\$ 2.8$ billion) have gone directly to finance the military component of the war against drug production, trafficking, and the organized criminal organizations associated with these activities (DNP, 2006, Table 2). Nevertheless, most available measures show that the availability of cocaine in consumer countries has not gone down significantly, nor has the price of cocaine shown any tendency to increase, as one might have expected given the intensification of the war on drugs (see Mejía and Posada, 2008). While the number of hectares of coca crops cultivated in Colombia has decreased from about 163.000 in 2000 to about 80.000 in 2006 - as a result of the intense aerial eradication campaigns- potential cocaine production in Colombia has only decreased from 695,000 kilograms per year in 2000 (right before the initiation of Plan Colombia) to roughly 610,000 kgs per year in 2006 (see UNODC, 2007). ${ }^{2}$ Consistent with the observed data just described on potential cocaine production and the relatively stable figures for consumption trends, the price of cocaine at the wholesale and retail levels in consumer countries has shown a relatively stable trend since $2000 .^{3}$

\footnotetext{
${ }^{1}$ Plan Colombia is the official name of a program that, among other things, provides the institutional framework for an strategic alliance between the Colombian and United States' governments to fight against the production and trafficking of illegal drugs (mainly cocaine), as well as the organized criminal organizations associated with these activities.

${ }^{2}$ During the same period, coca cultivation and cocaine production has increased slightly in the other two major producer countries, Bolivia and Peru. As a result, the total figures for potential cocaine production have remained relatively constant for the last 6-7 years (see UNODC, 2007; and Mejia and Posada, 2008).

${ }^{3}$ The wholesale and retail price of cocaine decreased rapidly between 1990 and 2000, but since then has remained relatively stable. See Costa-Storti and De Grauwe (2007) for an explanation of this phenomenon
} 
In the U.S., where about half of the cocaine produced in the world is consumed, the Federal Government currently spends about $\$ 12.5$ billion per year on different dimensions of the war on drugs. Approximately $\$ 7.7$ billion (about $60 \%$ ) is spent on policies aimed at reducing the supply of illegal drugs, such as domestic law enforcement, interdiction, and subsidies to drug producer countries; the other $\$ 4.8$ billion (about $40 \%$ ) is spent on policies aimed at reducing the demand for drugs, among them prevention campaigns and the treatment of drug addicts (see ONDCP, 2007, Table 1).

This paper develops a simple model of the war against illegal drugs in producer and consumer countries, where there are strategic interaction between the actors involved. These are the illegal drug producer and trafficker, the government of the drug producer country, the government of the drug consumer country, and a wholesale drug dealer in the border of the consumer country. We explicitly model the (wholesale) illegal drug market, which allows us to account for feedback effects between anti-drug policies and market outcomes (quantities and prices) likely to arise as a consequence of such large scale policy interventions as Plan Colombia.

In the producer country, the government comes into conflict with the drug producer and trafficker over the fraction of illegal drugs successfully produced and exported to the consumer country. In modelling the conflict between the government and the drug producer and trafficker, we abstract from explicitly modelling the conflict over the control of arable land necessary for the cultivation of illicit crops. ${ }^{4}$

Following the analysis of Grossman and Mejía (2008), we assume that the government of the drug consumer country uses both a stick and a carrot to strengthen the resolve of the government of the drug producer country in its war against illegal drugs. Additionally, the government of the drug consumer country uses prevention policies and subsidies to the government of the drug producer country in an attempt to minimize the amount of illegal drugs transacted in the market. While the former are aimed at reducing the demand for drugs through educational campaigns and by providing treatment to drug addicts, the latter are aimed at reducing the supply of illegal drugs coming from the drug producer country. Importantly, we study how anti-drug policies implemented in consumer and producer countries interact and affect one another's effectiveness. Our analysis shows how the

based on the increased globalization of the illegal drug markets.

${ }^{4}$ See Grossman and Mejia (2008), and Mejia and Restrepo (2008) for models in which this particular front of the war on drugs is explicitly studied. 
equilibrium allocation of resources between these two alternative policies crucially depends on the price elasticity of the demand for illegal drugs in the consumer country, on the effectiveness of prevention and treatment policies in reducing the demand for illegal drugs, and on the effectiveness of anti-drug policies in the producer country. In particular, we show how the relative allocation of resources to subsidies for the war on drugs in producer countries should be smaller when the following conditions exist: the demand for illegal drugs is relatively inelastic; prevention and treatment policies are relatively more effective; and the anti-drug policies being implemented in producer countries are relatively less effective.

We calibrate the model using the available data on the market for cocaine as well as data on the war against cocaine production, trafficking, and consumption in Colombia and the U.S. This calibration exercise allows us to recover some important unobservable parameters, such as the price elasticity of the demand for cocaine, the relative effectiveness of interdiction efforts, and the effectiveness of prevention policies in reducing the demand for cocaine.

One of the main contributions of this paper is that it provides a formal analytical framework for understanding the interactions between anti-drug policies implemented in producer and consumer countries. Importantly, by explicitly modelling the illegal drug market, we are able to account for the feedback effects between policies and market outcomes that are likely to arise as a result of large scale policy interventions such as those implemented under the war on drugs in producer and consumer countries. While there have been some important attempts at developing models of the war on drugs in both producer countries (Grossman and Mejía, 2008; and Mejía and Restrepo, 2008) and consumer countries (Becker, Grossman and Murphy, 2006; Rydell et al., 1996; and Caulkins, 1993, among others) there is no model in the literature that studies the interaction between anti-drug policies implemented in both consumer and producer countries. An important exception are the recent contributions by Chumacero (2006) and Costa-Storti and De Grauwe (2008). Chumacero (2008) develops a dynamic general equilibrium model of the war against illegal crops cultivation on the one hand, and that against illegal drug production, trafficking and consumption, on the other. ${ }^{5}$ His main contribution relies on the calibration of some key parameters of the model that are then used to assess the effects of three alternative

\footnotetext{
${ }^{5}$ The title of his paper, "Evo, Pablo, Tony, Diego, and Sonny", is quite suggestive of the fact that in it he studies the war on drugs at almost all stages: illegal crop cultivation (Evo), drug production (Pablo), drug trafficking (Tony), and drug consumption (Diego).
} 
policies - making illegal activities riskier, increasing the penalties for illegal activities, and legalization. Costa-Storti and De Grauwe (2008) address the issue of how globalization has reduced the retail price of illegal drugs during the last few decades, thus stimulating consumption.

The paper includes four sections, where this introduction is the first one. The second section, which constitutes the core of the paper, develops the model and explains the motivations and choices of the actors involved in the war on drugs. This section also derives the equilibrium of the model. Section three presents the results of the calibration of the model using the available data on the cocaine market, some key figures on the war against cocaine production and trafficking in Colombia, and data on the allocation of resources for prevention and treatment policies in the U.S. The fourth section concludes.

\section{The Model}

We model the war against illegal drugs as a sequential game. In the first stage of the game, the government of the drug consumer country chooses the optimal allocation of resources between prevention and treatment policies and enforcement policies. The latter take the form of a subsidy to the government of the drug producer country in order to strengthen its resolve in the war against illegal drug production and trafficking. Both sets of policies have the same objective, namely to reduce the amount of illegal drugs transacted in the consumer country at the wholesale level. While prevention and treatment policies target the reduction of demand, enforcement policies (subsidies to the producer country's government) aim at thwarting the availability of drugs in the consumer country - that is, at reducing the supply of illegal drugs. In the second stage of the game, the government of the drug producer country comes into conflict with drug producers and traffickers over the fraction of illegal drugs successfully exported.

We start with the second stage of the game, that is, with the conflict between the drug producer country's government and the illegal drug producer and trafficker over the fraction of illegal drugs successfully produced and exported. 


\subsection{The drug trafficking game}

\subsubsection{The interdiction technology}

Let $q$ be the fraction of drugs that survive the government's interdiction efforts. The interdiction technology is such that $q$ is determined endogenously by a standard context success function, ${ }^{6}$ by:

$$
q=\frac{s}{s+\phi r}
$$

where $r$ is the amount of resources that the government invests in the interdiction of drug shipments, such as radars, airplanes, go-fast boats, etc.; $s$ is the amount of resources that the drug trafficker invests in trying to avoid the interdiction of drug shipments, such as submarines, go-fast boats, airplanes, etc.; and $\phi>0$ is a parameter that captures the relative effectiveness of the resources invested by the government in trying to interdict illegal drug shipments. Note that the fraction, $q$, of illegal drugs that the drug trafficker successfully exports (equation 1) is an increasing and concave function of the ratio, $\frac{s}{\phi r}$.

\subsubsection{The drug trafficker}

The problem of the drug producer and trafficker is to choose the amount of resources to invest in trying to avoid the interdiction of drug shipments in order to maximize profits, $\pi_{T}$. More precisely, the drug trafficker's problem is given by:

$$
\max _{\{s\}} \pi_{T}=p_{c} q \lambda L-s .
$$

The first term in equation 2 is the price of drugs at the border of the consumer country, $p_{c}$, times the fraction of drugs that survives interdiction efforts, $q$, times the amount of drugs produced in the consumer country, $\lambda L$. This last term is the product of the productivity per hectare of land per year, $\lambda$ (for instance, the number of kilograms of illegal drugs that can be produced through the cultivation of the illegal crop on one hectare of land in one

\footnotetext{
${ }^{6} \mathrm{~A}$ contest success function (CSF) is "a technology whereby some or all contenders for resources incur costs in an attempt to weaken or disable competitors" (Hirshleifer, 1991). In this particular case, the CSF determines the fraction of illegal drugs that are succesfully exported to the consumer country as a function of the government's interdiction efforts and the drug trafficker's efforts to avoid the government's interdiction of drug shipments. See Skaperdas (1996) and Hirshleifer (2001) for a detailed explanation of the different functional forms of CSFs.
} 
year $\left.{ }^{7}\right)$, times the number of hectares of land under the drug producer's control, L. ${ }^{8}$ The last term, $s$, denotes the amount of resources invested by the drug trafficker in trying to avoid the interdiction of illegal drug shipments. ${ }^{9}$

The first order condition of the drug trafficker's problem in equation 2 is:

$$
\frac{\partial \pi_{T}}{\partial s}=0 \quad \Longleftrightarrow \quad \frac{\phi r}{(s+\phi r)^{2}} p_{d} \lambda L=1 .
$$

Equation 3 describes the best reaction function of the drug trafficker to every possible choice of resources employed by the government in its interdiction efforts, $r$.

\subsubsection{The government of the drug producer country}

Following Grossman and Mejía (2008), we assume that the drug consumer country's government uses both a stick and a carrot in an attempt to strengthen the resolve of the drug producer country's government in its war against illegal drugs. The stick is the threat that the interested outsider will label the country as a narco-state and, as a result, it will be ostracized by the international community.

Let us assume that, from the perspective of the drug producer country's government, the decision of the drug consumer country to apply the label narco-state includes a stochastic element. ${ }^{10}$ To allow for this stochastic element, we assume that the drug producer country's

\footnotetext{
${ }^{7}$ In the case of Colombian cocaine, this yield/hectare/year ratio was, for 2006, about $7.4 \mathrm{~kg}$ of cocaine per hectare (see UNODC, 2006).

${ }^{8}$ See Grossman and Mejia (2008), and Mejia and Restrepo (2008) for models that include conflicts between the government and drug producers over the control of arable land suitable for cultivating illegal crops.

${ }^{9}$ Equation 2 implicitly assumes that the cost of producing illegal drugs is zero. In reality, the main costs of illegal drug production and trafficking are those associated with avoiding the eradication of illegal crops and the interdiction of drug shipments; the cost of actually producing illegal drugs is negligible. This assumption is made for analytical simplicity, and does not modify the main results obtained below.

${ }^{10}$ What we have in mind is the Drug Certification Process, which was established in 1986 and whereby, each year, the U.S. government evaluates the level of cooperation and meassures taken by all illegal drug producer and transit countries against illegal drug production and trafficking. Those countries that are not certified face a number of consequences with direct and indirect costs. For instance, non-certification "requires the U.S. to deny sales or financing under the Arms Export Control Act; deny non-food assistance under Public Law 480; deny financing by the Export-Import Bank, and withhold most assistance under the FAA with the exception of specified humanitarian and counternarcotics assistance. The U.S. must also vote against proposed loans from six multilateral development banks." see: http://www.usembassy-
} 
government perceives the probability of its being labeled a narco-state to be equal to the ratio $D / \lambda L$, where $\lambda L$ is the amount of drugs that could potentially be produced and exported annually, and $D=q \lambda L$ is the actual production and exportation of illegal drugs. Let $c$ denote the annual cost in dollars that the drug producer country's government anticipates would result from being labeled a narco-state. Thus, the expected annual cost associated with the possibility of being labeled a narco-state equals the product of $c$ and $q(D / \lambda L=q)$.

The carrot employed by the drug consumer country is a subsidy to the drug producer country's armed forces. This subsidy is a fraction, $1-\omega$, of the resources that the drug producer country allocates to the interdiction of drug shipments, $r$.

The objective of the drug producer country's government is to minimize the sum of the costs associated with illegal drug production and trafficking. These costs are given by the sum of the expected cost of being labeled a narco-state and the cost of fighting the war against drug production and trafficking. This cost is given by the amount of resources invested by the government in interdiction efforts, $r$, times the fraction actually paid by the government, $\omega$. Thus, the problem for the government of the drug producer country is:

$$
\min _{\{r\}} C_{T}=c q+\omega r
$$

where $q$ is determined by equation 1 .

The first order condition for the government's problem is given by:

$$
\frac{\partial C_{T}}{\partial r}=0 \quad \Longleftrightarrow \quad \frac{-\phi s}{(s+\phi r)^{2}} c+\omega=0 .
$$

Equation 5 is the government's best reaction function to every possible choice of resources employed by the drug trafficker in avoiding the interdiction of illegal drug shipments, $s$.

\subsection{The drug trafficking equilibrium}

Using equations 3 and 5 , we can find a LOCUS of points in the space $\left(\frac{r}{s}, p_{c}\right)$ for which the drug trafficking game is in equilibrium. ${ }^{11}$

$\overline{\text { mexico.gov/bbf/bfdossier_certDrogas.htm. }}$.

${ }^{11}$ Recall that $r, s$, and $\bar{p}_{c}$ are endogenous variables of the model. 
Definition 1 (GE LOCUS): All pairs $\left(\frac{r}{s}, p_{c}\right)$ that satisfy the following expression represent possible equilibria of the drug trafficking game:

$$
\frac{r}{s}=\frac{c}{p_{c} \lambda L \omega}
$$

According to the expression for the GE LOCUS, a higher price for the illegal drug in the consumer country leads to lower relative spending by the drug producer country's government on the war on drugs. This is so because a larger $p_{c}$ increases the marginal returns for the drug trafficker of allocating resources to avoiding interdiction; this naturally induces the trafficker to fight relatively harder than the government. ${ }^{12}$

Using the expression in equation 6, and inserting it into the drug trafficker's reaction function (equation 3), we can derive an explicit expression for the government's and the drug trafficker's level of expenses in the war on drugs (both as functions of the parameters of the model and the price of drugs in the consumer country, yet to be determined). These two allocations are given, respectively, by:

$$
r=\frac{\phi c^{2}\left(\lambda L \omega p_{c}\right)^{2}}{\lambda L \omega^{2} p_{c}\left(\lambda L \omega p_{c}+\phi c\right)^{2}}
$$

and,

$$
s=\frac{\phi c\left(\lambda L \omega p_{c}\right)^{2}}{\omega\left(\lambda L \omega p_{c}+\phi c\right)^{2}} .
$$

In turn, if we insert $r$ and $s$ from equations 7 and 8 into equation 1 , the fraction of illegal drugs that survives the government's interdiction efforts in equilibrium (that is, the fraction of drugs exported successfully) is given by:

$$
q=\frac{\lambda L \omega p_{c}}{\lambda L \omega p_{c}+\phi c} .
$$

The fraction of drugs that survives the government's interdiction efforts is an increasing and concave function of the price of drugs; of the fraction of the expenses in interdiction efforts paid by the drug producer country's government, $\omega$; and of potential cocaine production, $\lambda L$. A higher relative efficiency in the government's interdiction of drug shipments, $\phi$,

\footnotetext{
${ }^{12}$ This result arises from the assumption that the cost to the drug producer country's government from illegal drug production and trafficking does not depend on the price of drugs, but on the drugs succesfully produced and exported relative to potential production.
} 
or a larger cost of being labeled a narco-state, $c$, decreases the fraction of drugs successfully exported.

We now turn to a description of the drug market equilibrium.

\subsection{The drug market equilibrium}

First, let us assume that the demand for drugs at the border of the consumer country is given by a general demand function of the form:

$$
Q_{c}^{d}=\frac{a(l)}{p_{c}^{b}},
$$

where $Q_{c}^{d}$ denotes the demand for drugs by drug dealers at the border of the consumer country, and $a(l) \geq 0$, with $l$ denoting the allocation of resources to prevention policies (educational campaigns, treatment programs for drug addicts, etc.) aimed at reducing the demand for illegal drugs in the consumer country. Naturally, we assume that $a^{\prime}(l)<0$ that is, as more resources are allocated to prevention and treatment policies, the demand for illegal drugs decreases (i.e., the demand for drugs shifts to the left). $p_{c}$ is the price of illegal drugs at the border of the consumer country, and $b$ is the price elasticity of demand for illegal drugs at the wholesale level at the border of the consumer country.

Second, the supply of drugs in the consumer country is given by:

$$
Q_{c}^{s}=\frac{s}{s+\phi r} \lambda L
$$

According to equation 11, the supply of drugs in the consumer country is equal potential drug production, $\lambda L$, multiplied by the fraction of the production not interdicted, $q$ (see equation 1). Note that equation 11 expresses the supply of drugs in the consumer country as a function of the ratio of expenses in the war on drugs in the producer country, $r / s$.

In the drug market equilibrium, we must have that $Q_{c}^{d}=Q_{c}^{s}$. Equating 10 and 11 and

rearranging, we are now able to define a LOCUS of points in the space $\left(\frac{r}{s}, p_{c}\right)$ for which the illegal drug market at the border of the consumer country is in equilibrium.

Definition 2 (ME LOCUS): All pairs $\left(\frac{r}{s}, p_{c}\right)$ that satisfy the following expression represent possible equilibria of the drug market at the border of the consumer country:

$$
\frac{r}{s}=\frac{\lambda L p_{c}^{b}}{\phi a(l)}-\frac{1}{\phi}
$$


In contrast with the GE Locus, under the ME Locus, a higher price of illegal drugs at the border of the consumer country leads to a larger relative spending by the government of the drug producer country in the war on drugs. This positive relationship between the ratio of spendings in the war on drugs and the price of the illegal drug in the consumer country arises because a higher ratio $\frac{r}{s}$ means a lower supply of drugs and, given the demand, the price of the illegal drug, $p_{c}$, has to increase in order for the drug market to remain in equilibrium.

We can now use both LOCI described above to graphically represent the equilibrium of the second stage of the game. Recall that the GE Locus describes all pairs of points $\left(\frac{r}{s}, p_{c}\right)$ for which the drug trafficking game is in equilibrium, while the ME Locus describes all pairs of points $\left(\frac{r}{s}, p_{c}\right)$ for which the drug market is in equilibrium. The two LOCI are represented in Figure 1.

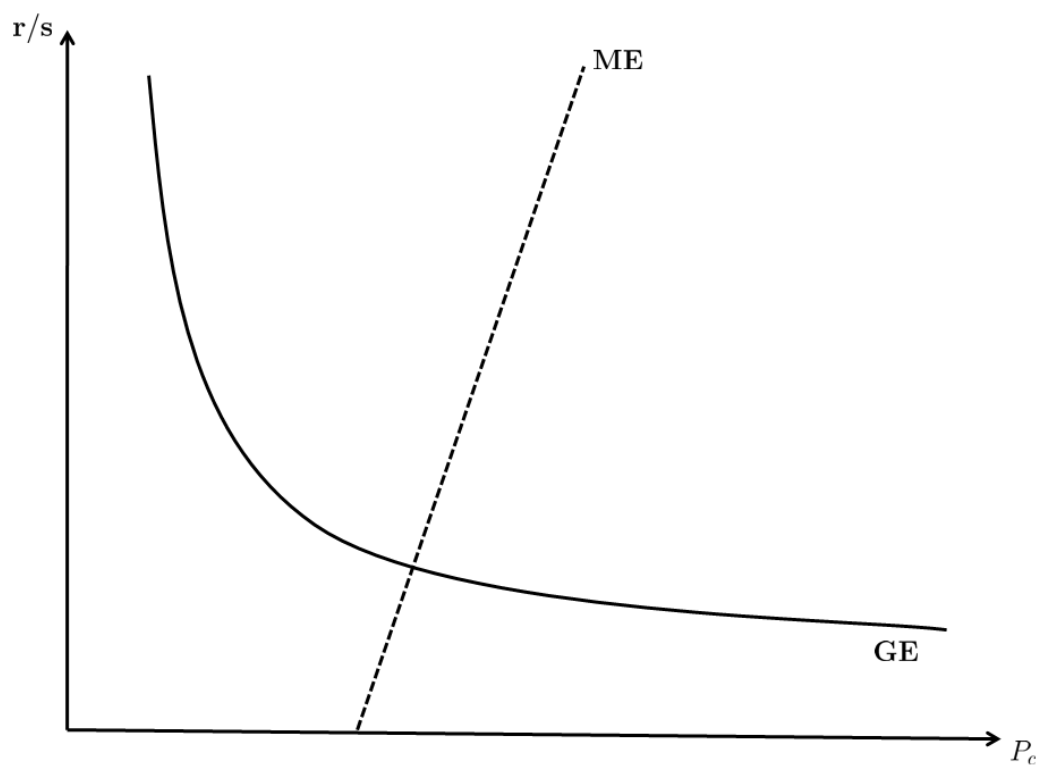

Figure 1: The GE and ME LOCI.

We can now study how changes in the parameters of the model shift each of the two LOCI, and how the relative allocation of resources to the war on drugs and the price of illegal drugs change as some of the structural parameters of the model change. At this point, we will focus on changes in the allocation of resources with respect to prevention and treatment policies, and enforcement policies in the form of subsidies to the drug producer country's 
government (which will be the focus of our analysis once we turn to the analysis of the first stage of the game). Figure 2 shows how the price of illegal drugs and the relative spending on the war on drugs change as $l$ increases (i.e., as $a$ decreases). Figure 3 shows the effect of a decrease in $\omega$ (an increase in the subsidy to the drug producer country's armed forces in its war against illegal drug production and trafficking). While an increase in spending on prevention policies aimed at reducing consumption in the consumer country reduces the equilibrium price of drugs and increases the government's relative spending on the war on drugs (thereby reducing the equilibrium fraction of drugs successfully exported), an increase in the subsidy increases the equilibrium price of drugs at the border of the consumer country and the government's relative spending on the war on drugs. Note that an increase in the subsidy generates two opposing forces on the ratio $r / s$ - it increases the price of illegal drugs, and thus increases the incentives for the drug traffickers to invest resources in evading interdiction (as the price of drugs increases); and it increases the incentives for the drug producer country's government to invest resources on the war on drugs, as the marginal cost of doing so goes down. The net effect is an increase in the ratio $r / s$ (as shown in Figure 3). Importantly, an increase in the subsidy from the drug consumer country induces an increase in the total resources invested on the war on drugs, $r+s$ that is, an increase in the subsidy to the drug producer country's government increases the intensity of the conflict as measured by the sum of resources invested by the two actors involved in this war. 


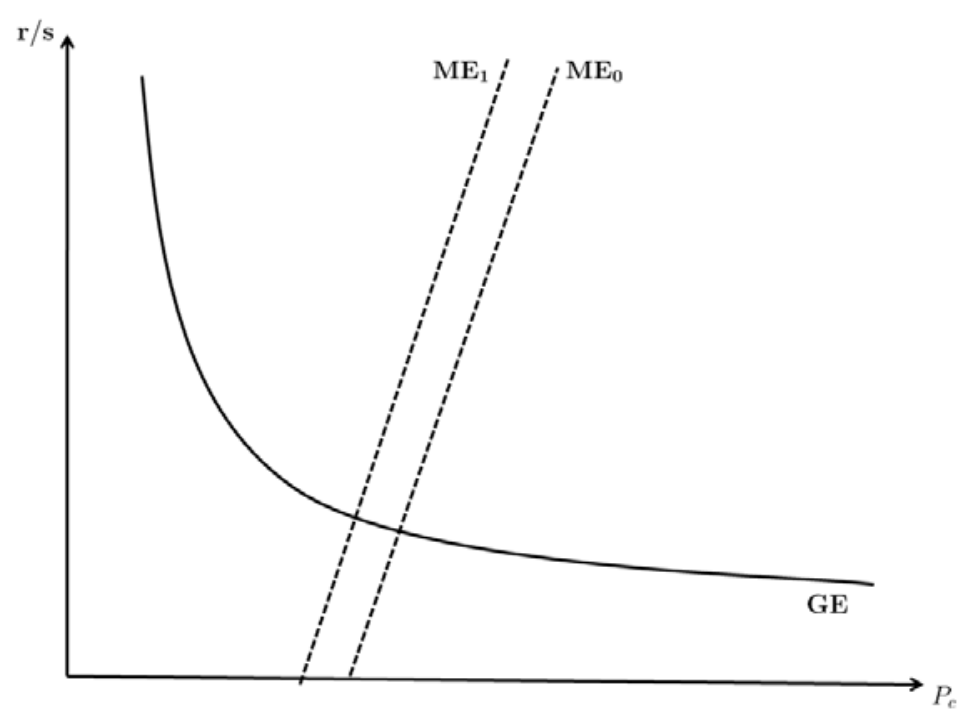

Figure 2: The effects of an increase in $l$ (decrease in $a$ ).

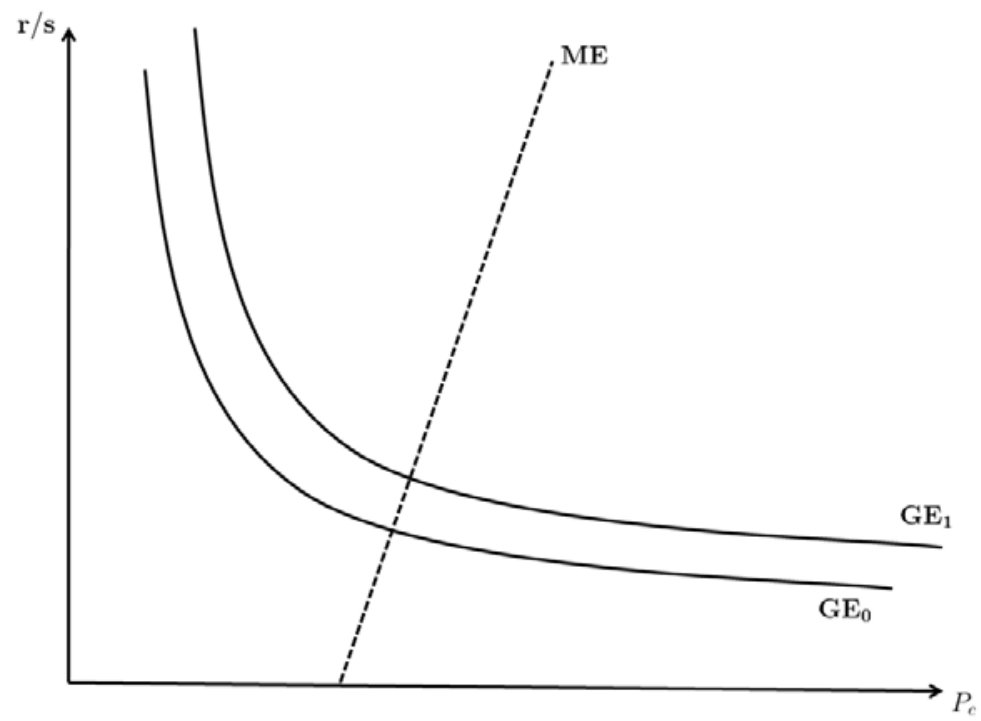

Figure 3: The effects of an increase in the subsidy (decrease in $\omega$ ).

The representation of the equilibrium of the model in terms of the two LOCI described above is helpful for understanding how changes in the parameters of the model affect the relative allocation of resources to the war on drugs and, correspondingly, the fraction of drugs successfully exported. However, the equilibrium of the model can also be represented 
using a standard supply and demand framework. Using equation 9, the supply of drugs at the border of the consumer country (that is, the supply of drugs net of interdiction) is given by:

$$
Q_{c}^{s}=\frac{(\lambda L)^{2} \omega p_{c}}{\lambda L \omega p_{c}+\phi c} .
$$

In turn, the demand for drugs is given by equation 10. The graphical representation of the equilibrium at this stage of the game in a simple supply and demand figure is depicted in Figure 4.

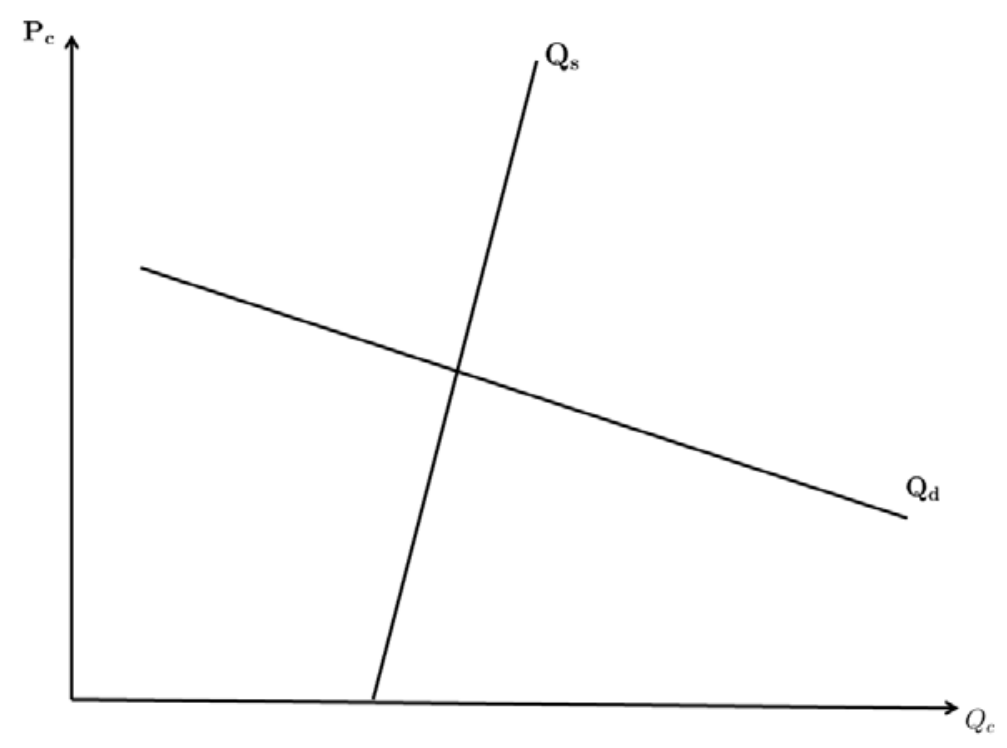

Figure 4: Drug market equilibrium: First stage.

Solving for $p_{c}$ in both expressions and making $Q_{c}^{s}=Q_{c}^{d}=Q_{c}$, the equilibrium quantity of drugs is determined by the following implicit equation, which depends on the parameters of the model as well as on the two choice variables for the drug consumer country's government, $l$ and $\omega$ (yet to be determined in the next subsection).

$$
F\left(Q_{c}, l, \omega\right)=Q_{c}^{\frac{1+b}{b}} \phi c+a(l)^{\frac{1}{b}} \lambda L \omega\left(Q_{c}-\lambda L\right)=0 .
$$

Using the expression for the equilibrium quantity of drugs in the second stage of the game, we are now able to determine the sign of the effect of changes in the parameters of 
the model on the equilibrium quantity of drugs. The following are the main comparative statics results at this stage:

. $\frac{\partial Q_{c}}{\partial l}=\frac{-\partial F / \partial l}{\partial F / \partial Q_{c}} \leq 0$. An increase in prevention policies aimed at reducing the demand for drugs in the drug consumer country decreases the amount of illegal drugs transacted in equilibrium. On the one hand, $\partial F / \partial Q_{c}>0$, and, on the other hand, $\partial F / \partial l>0$ because $Q_{c}-\lambda L<0$. Recall that $\lambda L$ is potential drug production whereas $Q_{c}$ is the amount of drugs transacted in equilibrium. With at least some interdiction (that is, with $q<1$, as is in fact the case in equilibrium (see equation 9)), the amount of drugs transacted in equilibrium is always lower than potential drug production. Conversely, a decrease in $l$ (i.e., an increase in $a$ ) increases the amount of illegal drugs transacted. We elaborate more on this point in the next section of the paper, when we consider the optimal allocation of resources to prevention policies in the drug consumer country.

- $\frac{\partial Q_{c}}{\partial \omega}=\frac{-\partial F / \partial \omega}{\partial F / \partial Q_{c}} \geq 0$. A decrease in the subsidy to the drug producer country in its war against illegal drugs (that is, a lower $1-\omega$ ) increases the quantity of illegal drugs transacted in equilibrium. Again, this result follows from the fact that $Q_{c}-\lambda L<0$. Intuitively, a larger marginal cost for the interdiction efforts of the drug producer country's government will induce it to spend less resources on the interdiction of drug shipments. As a result, the supply of drugs in the consumer country (net of interdiction) will increase. Again, this point will be elaborated in more detail in the next section of the paper.

$\frac{\partial Q_{c}}{\partial \phi}=\frac{-\partial F / \partial \phi}{\partial F / \partial Q_{c}} \leq 0$ and $\frac{\partial Q_{c}}{\partial c}=\frac{-\partial F / \partial c}{\partial F / \partial Q_{c}} \leq 0$. An increase in either the relative efficiency of the drug producer country's government in the war on drugs or an increase in the cost to the drug producer country of being labeled a narco-state leads to a negative shift in the supply of drugs. This is because the drug producer country's government will allocate relatively more resources to its interdiction efforts. As a result, the equilibrium fraction of drugs successfully exported (equation 9) will decrease.

$$
\cdot \frac{\partial Q_{c}}{\partial \lambda}=\frac{-\partial F / \partial \lambda}{\partial F / \partial Q_{c}} \geq 0, \text { and } \frac{\partial Q_{c}}{\partial L}=\frac{-\partial F / \partial L}{\partial F / \partial Q_{c}} \geq 0 . \text { An increase in } \lambda, \text { the productivity }
$$
per hectare of land used for the cultivation of illegal crops, or an increase in $L$, the land under the control of drug producers, increases the amount of drugs produced and exported in equilibrium. An increase in productivity or in the amount of land controlled by drug 
producers shifts the supply curve outwards. As a result, the price of drugs goes down and the quantity of drugs in equilibrium goes up.

We now turn to an analysis of the first stage of the game - that is, the stage at which a choice is made between prevention policies and policies aimed at curtailing the supply of drugs by increasing subsidies for the drug producer country's interdiction efforts.

\subsection{Anti-drug policies in the consumer country: prevention and treatment ver- sus enforcement}

During the first stage of the game, the objective of the drug consumer country's government is to minimize the amount of illegal drugs transacted at its border. To achieve this objective, the drug consumer country's government combines prevention and treatment policies, aimed at reducing the demand for illegal drugs, and enforcement policies in the form of subsidies to the armed forces of the drug producer country in its war against illegal drug production and trafficking.

More formally, the objective of the drug consumer country's government is:

$$
\begin{aligned}
\min _{\{l, d\}} Q_{c} \quad \text { subject to } & : \\
l+d & =M, \text { and } \\
d & =(1-\omega) r^{*}
\end{aligned}
$$

where $Q_{c}$ is the quantity of illegal drugs transacted at the border of the consumer country in equilibrium, $M$ is the consumer country's total budget for prevention and enforcement policies, $l$ is the allocation of resources to prevention policies (i.e. the reduction of demand), and $d$ is the total amount of resources that the drug consumer country grants to the drug producer country in the form of subsidies to finance its expenses in its war against illegal drug trafficking. The total amount of subsidies, $d$, is equal to the marginal subsidy, $1-\omega$, times the resources spent by the drug producer country on the war against drug production and trafficking, $r^{*}$ - that is, $d$ is the total amount of resources allocated by the drug consumer country's government to reducing the supply of illegal drugs coming from the drug producer country.

Using equations 7 and 13 , and the fact that $d=(1-\omega) r^{*}$, we can solve for $\omega$ in terms of the parameters of the model, the amount in subsidies provided by the drug consumer 
country's government, $d$, and the quantity of illegal drugs transacted, $Q_{c}$, as:

$$
\omega=\frac{\frac{c Q_{c}}{\lambda L}\left(1-\frac{Q_{c}}{\lambda L}\right)}{d+\frac{c Q_{c}}{\lambda L}\left(1-\frac{Q_{c}}{\lambda L}\right)}
$$

Replacing the expression for $\omega$ obtained in equation 16 into equation 14 allows us to express the quantity of drugs transacted in equilibrium (that is the equilibrium level of $Q_{c}$ ) as a function of the parameters of the model and the two instruments of the drug consumer country's government, $l$ and $d$, in the following implicit function:

$$
S\left(Q_{c}, l, d\right)=Q_{c}^{\frac{1+b}{b}} \phi c+a(l)^{\frac{1}{b}} \lambda L \frac{\frac{c Q_{c}}{\lambda L}\left(1-\frac{Q_{c}}{\lambda L}\right)}{d+\frac{c Q_{c}}{\lambda L}\left(1-\frac{Q_{c}}{\lambda L}\right)}\left(Q_{c}-\lambda L\right)=0 .
$$

Using the implicit function in equation 17 - which determines the equilibrium quantity of illegal drugs as a function of the two instruments of the drug consumer country's government - the optimal allocation of resources between prevention and enforcement policies is determined by the following optimality condition: ${ }^{13}$

$$
\frac{\partial S\left(Q_{c}, l, d\right)}{\partial l}=\frac{\partial S\left(Q_{c}, l, d\right)}{\partial d}
$$

Intuitively, the optimally condition in equation 18 states that the drug consumer country's government will adjust the allocation of resources between prevention and deterrence policies until the two are equally effective at the margin in reducing $Q_{c}$.

Deriving the expressions for $\partial S(.) / \partial l$ and $\partial S(.) / \partial d$ from equation 17, the optimality condition in equation 18 becomes (after some algebraic manipulation):

$$
\frac{1}{b} \frac{a^{\prime}(l)}{a(l)}=-\frac{1}{d+\frac{c Q_{c}}{\lambda L}\left(1-\frac{Q_{c}}{\lambda L}\right)}
$$

In order to find a close form solution to the problem of the drug consumer country's government, let us assume that:

\footnotetext{
${ }^{13}$ This optimality condition is obtained using the implicit function theorem to find the expressions for $\frac{\partial Q_{c}}{\partial l}$ and $\frac{\partial Q_{c}}{\partial d}$.
} 


$$
a(l)=\frac{A}{l^{\theta}}
$$

where $A>0$, and $\theta>0$ is a parameter that captures the efficiency of prevention policies. More precisely, parameter $\theta$ captures the percentage of reduction in the demand for drugs as a result of a $1 \%$ increase in spending on treatment and prevention policies.

Using the functional form for $a(l)$ from equation 20, the optimality condition in equation 19 becomes:

$$
\frac{1}{b} \frac{\theta}{l}=\frac{1}{d+\frac{c Q_{c}}{\lambda L}\left(1-\frac{Q_{c}}{\lambda L}\right)} .
$$

Finally, using the budget constraint of the drug consumer country's government together with equation 21, the optimal allocation of resources between treatment and prevention policies on the one hand, and subsidies to the drug producer country's government on the other hand, is given (respectively) by:

$$
l^{*}=\frac{\theta}{b+\theta} M+\frac{\theta}{b+\theta} \frac{c Q_{c}}{\lambda L}\left(1-\frac{Q_{c}}{\lambda L}\right),
$$

and,

$$
d^{*}=\frac{b}{b+\theta} M-\frac{\theta}{b+\theta} \frac{c Q_{c}}{\lambda L}\left(1-\frac{Q_{c}}{\lambda L}\right) .
$$

A few things in equations 22 and 23 are worth noticing. First, if the demand for drugs becomes more inelastic (i.e., if $b$ is lower), the optimal allocation of resources shifts towards prevention policies and away from enforcement policies. This result is in line with that of Becker et al. (2006). ${ }^{14}$ Second, a higher $\theta$ - that is, a higher efficiency for treatment and prevention policies in reducing the demand for illegal drugs - increases the optimal allocation of resources to prevention policies and decreases that to enforcement policies.

Replacing the optimal allocation $d^{*}$ from equation 23 into equation 24, which describes the equilibrium value of $\omega$, we get:

\footnotetext{
${ }^{14} \mathrm{~A}$ sufficient condition for this result to be true is that $Q_{c} /(\lambda L)<1 / 2$. However, even if this condition does not hold, the result might still hold for a broad range of parameter values. The details of this calculation are available from the author upon request.
} 


$$
\omega^{*}=\frac{\frac{c Q_{c}}{\lambda L}\left(1-\frac{Q_{c}}{\lambda L}\right)}{\frac{b}{b+\theta}\left[M+\frac{c Q_{c}}{\lambda L}\left(1-\frac{Q_{c}}{\lambda L}\right)\right]} .
$$

Replacing the optimal allocation of resources to prevention policies, $l^{*}$, from equation 22 , into equation 20 , we get:

$$
a^{*}=\frac{A}{\left[\frac{\theta}{b+\theta}\left(M+\frac{c Q_{c}}{\lambda L}\left(1-\frac{Q_{c}}{\lambda L}\right)\right)\right]^{\theta}}
$$

Finally, replacing equations 24 and 25 into equation 14, the equilibrium level of illegal drugs transacted in equilibrium is described by the following implicit equation (this time only as a function of the parameters of the model):

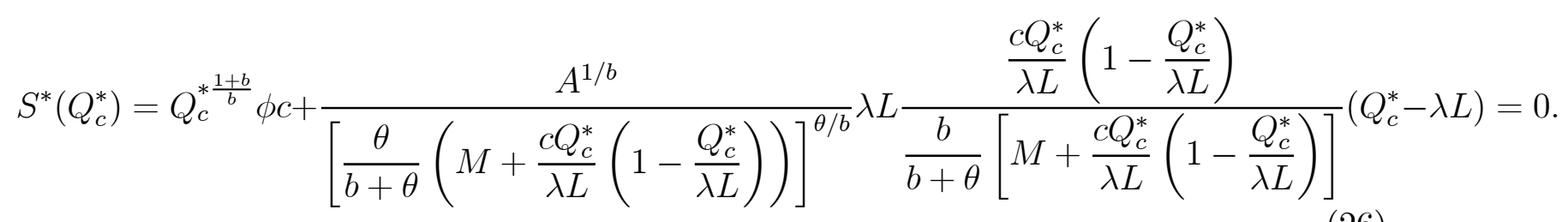

\section{Calibration strategy and results}

In this section, we use data from the market for cocaine at the wholesale level, as well as available data on the outcomes of Plan Colombia, in order to calibrate the unobservable parameters of the model.

Table 1 briefly describes some of the data used in calibrating the parameters of the model. ${ }^{15}$ All the data that we use is for 2006, though the data on the Colombian and U.S. allocation of resources for the war on drugs under Plan Colombia is not available on a yearly basis, but as average allocations during the Plan Colombia's duration. We don't have a direct estimate for the U.S. allocation of resources on prevention and treatment policies, $l$, in reducing the demand for cocaine. However, we do know the total amount of resources spent by the U.S. government on policies aimed at reducing the demand for

\footnotetext{
${ }^{15}$ For a thorough description of the data on the market for cocaine, the war on drugs, etc., see Mejia and Posada (2008).
} 
illegal drugs - about $\$ 3,8$ billion in 2006 (see ONDCP, 2007). We assume that about $7 \%$ of these resources (or about $\$ 250$ million) are spent on reducing cocaine consumption.

Table 1

$\begin{array}{cccc}\text { Definition } & \text { Variable } & \text { Observed } & \text { Source } \\ \text { Drug seizures }(\mathrm{kgs}) & (1-q) \lambda L & 98,000 & \text { UNODC, 2007 } \\ \text { Cocaine price/kg at the U.S. border }(\$ / \mathrm{kg}) & p_{c} & 32,500 & \text { UNODC, 2007 } \\ \text { Colombian cocaine in the wholesale market } & Q_{c} & 531,000 & \text { UNODC, } 2007 \\ \text { US budget for prevention }(\$) & l & 250 \text { million } & \text { ONDCP, } 2007 \\ \text { US budget for Plan Colombia }(\$) & d & 465 \text { million } & \text { DNP, } 2006 \\ \text { Hectares of land with coca crops (has) } & L & 85.000 & \text { UNODC, } 2007 \\ \text { Kilos of cocaine/hectare/year (kgs) } & \lambda & 7,4 & \text { UNODC, 2007 } \\ \text { Colombian expenditures on the war on drugs } & \omega r & 561,6 \text { million } & \text { DNP, 2006 }\end{array}$

Using equations $7,9,20,22,24$, and 26 together, we can jointly calibrate $b, \theta, \phi, \omega, A$, and $c$. Table 2 presents the results from the calibration exercise.

Table 2

$\begin{array}{cc}\text { Parameter } & \text { Calibrated value } \\ b & 0.66 \\ \theta & 0.171 \\ \phi & 0.615 \\ \omega & 0.518 \\ A & 4.9 \times 10^{8} \\ c & \$ 3.8 \text { billion }\end{array}$

The estimated value for the price elasticity of demand for cocaine, 0.66, denotes a relatively inelastic demand. In some ways, this result reaffirms the view that the demand for hard drugs is relatively inelastic. This estimate for the price elasticity of demand at the wholesale level is very close to that found by Mejía and Restrepo (2008), about 0.67.

$\theta$, a parameter that captures the efficiency of prevention policies in reducing the demand for cocaine in the U.S., is estimated to be about 0.171. This parameter can be interpreted as the percentage of reduction in the demand for cocaine at the wholesale level resulting after a $1 \%$ increase in the resources devoted to prevention and treatment policies. That is, 
a $1 \%$ increase in prevention and treatment policies would decrease the demand for illegal drugs at the wholesale level by about $0.17 \%$. Parameter $\phi$, which captures the relative efficiency of the drug producer country's government on the war on drugs, is calibrated to be about 0.61. Conversely, the resources spent by drug producers and traffickers on the war on drugs are 1.62 times more efficient (1/0.61) than those resources invested by the drug producer country's government on the war on drugs.

Our estimate for $\omega$ implies that the U.S. has funded about $48.2 \%(1-\omega)$ of the Colombian expenses on the war on drugs.

Finally, we calibrate the cost to the Colombian government of being labelled a narcostate, $c$, to be about $\$ 3.8$ billion, which is about $2 \%$ of current Colombian GDP. This number lies within the range for this variable assumed in Grossman and Mejía (2008).

\section{Concluding remarks}

The model developed in this paper is a first step towards understanding the interrelationship between anti-drug policies in consumer and producer countries. Modelling the motivations and choices of the actors involved in the war on drugs using economic tools (more precisely, game theory tools) is an important step towards understanding the outcomes of this war. This paper develops a simple model of the war on drugs in producer and consumer countries in order to explain how resources are allocated by the different actors involved in it, the equilibrium outcomes, and the response of these outcomes to exogenous changes in some of the key parameters of the model. Importantly, we explicitly model illegal drug markets, which allows us to account for the feedback effects between policy changes, prices, and the strategic responses of the different actors involved that are likely to arise as a result of large scale policy interventions such as Plan Colombia.

We use the available data on the cocaine market at the wholesale level in consumer countries as well as outcomes from the war on drugs under Plan Colombia to calibrate the unobservable parameters of the model. In particular, according to the calibration results, the price elasticity of the demand for cocaine at the wholesale level in consumer countries is about 0.66, which confirms the view that the demand for drugs is inelastic. Additionally, we estimate that a $1 \%$ increase in the resources invested in prevention and treatment policies in the U.S. would decrease the demand for cocaine at the wholesale level by about $17 \%$. 


\section{References}

Becker, G., Murphy, K. and Grossman, M., 2006. The market for Illegal Goods: The case of Drugs. Journal of Political Economy 114(1), 38-60.

Caulkins, J., 1993. Local Drug Markets' Response to Focused Police Enforcement. Operations Research 41(5), 848-63.

Chumacero, R., 2006. Evo, Pablo, Tony, Diego, and Sonny. Mimeo, Universidad de Chile.

DNP, 2006. Balance Plan Colombia: 1999-2005. Departamento Nacional de Planeacion, Colombia. Septiembre.

Costa Storti, C., and De Grauwe, P., 2007. Globalization and the Price Decline of Illicit Drugs. CESifo WP \#1990, May.

Costa Storti, C., and De Grauwe, P., 2008. Modelling the Cocaine and Heroin Markets in the Era of Globalization and Drug Reduction Policies. Paper presented at the CESifo Venice summer institute, 2008.

Departamento Nacional de Planeación (DNP), 2006. Balance Plan Colombia: 19992005. Septiembre.

Grossman, H. and Mejía, D., 2008. The War Against Drug Producers. Economics of Governance 9(1), 5-23.

Hirshleifer, J., 1991. The Technology of Conflict as an Economic Activity. American Economic Review Papers and Proceedings 81 (2), 130-134.

Hirshleifer, J., 2001. Conflict and Rent-Seeking Success Functions: Ratio vs. Difference Models of Relative Success, in Hirshleifer, J., The Dark Side of Force, ch. 5, 89-101.

McDermott, J. (2004); New Super Strain of Coca Plant Stuns Anti-Drug Officials, The Scotsman, Scotland, August 27.

Mejía, D. and Posada., C.E., 2008. Cocaine Production and Trafficking: What do we know?. Policy Research Working Paper 4618. The World Bank.

Mejía, D. and Restrepo, P., 2008. The War on Illegal Drug Production and Trafficking: An Economic Evaluation of Plan Colombia. Documento CEDE 2008-19, Universidad de los Andes.

Office of National Drug Control Policy (ONDCP), 2007. National Drug Control Strategy, FY 2007 Budget Summary.

Rydell, P., Caulkins, J., and Everingham, S., 1996. Enforcement or Treatment: Mod- 
elling the Relative Efficacy of Alternatives for Controlling Cocaine. Operations Research 44(5), 687-95.

Skaperdas, S., 1996. Contest Success Functions. Economic Theory 7, 283-290.

United Nations Office for Drug Control (UNODC), 2007. World Drug Report. Available at: http://www.unodc.org/unodc/en/data-and-analysis/WDR.html 


\section{CESifo Working Paper Series}

for full list see www.cesifo-group.org/wp

(address: Poschingerstr. 5, 81679 Munich, Germany, office@cesifo.de)

2397 Mohammad Reza Farzanegan, Illegal Trade in the Iranian Economy: Evidence from a Structural Model, September 2008

2398 Olivier Bos, Charity Auctions for the Happy Few, September 2008

2399 Robert S. Chirinko and Debdulal Mallick, The Marginal Product of Capital: A Persistent International Puzzle, September 2008

2400 Ben D'Exelle and Arno Riedl, Elite Capture, Political Voice and Exclusion from Aid: An Experimental Study, September 2008

2401 Torben M. Andersen and Joydeep Bhattacharya, On Myopia as Rationale for Social Security, September 2008

2402 Fabienne Llense, French CEO Compensations: What is the Cost of a Mandatory Upper Limit?, September 2008

2403 Valentina Bosetti, Carlo Carraro, Alessandra Sgobbi and Massimo Tavoni, Delayed Action and Uncertain Targets. How Much Will Climate Policy Cost?, September 2008

2404 Robert G. Chambers, Rolf Färe, Shawna Grosskopf and Michael Vardanyan, Generalized Quadratic Revenue Functions, September 2008

2405 Leonidas Enrique de la Rosa, Overconfidence in a Career-Concerns Setting, September 2008

2406 Marcus Drometer and Johannes Rincke, The Design of Political Institutions: Electoral Competition and the Choice of Ballot Access Restrictions in the United States, September 2008

2407 Markku Lanne and Helmut Lütkepohl, Stock Prices and Economic Fluctuations: A Markov Switching Structural Vector Autoregressive Analysis, September 2008

2408 Thomas L. Brewer, International Energy Technology Transfers for Climate Change Mitigations, September 2008

2409 Alexander Kemnitz, Native Welfare Losses from High Skilled Immigration, September 2008

2410 Xavier Vives, Strategic Supply Function Competition with Private Information, September 2008

2411 Fabio Padovano and Roberto Ricciuti, The Political Competition-Economic Performance Puzzle: Evidence from the OECD Countries and the Italian Regions, September 2008 
2412 Joan Costa-Font and Mireia Jofre-Bonet, Body Image and Food Disorders: Evidence from a Sample of European Women, September 2008

2413 Thorsten Upmann, Labour Unions - To Unite or to Separate?, October 2008

2414 Sascha O. Becker and Ludger Woessmann, Luther and the Girls: Religious Denomination and the Female Education Gap in $19^{\text {th }}$ Century Prussia, October 2008

2415 Florian Englmaier and Stephen Leider, Contractual and Organizational Structure with Reciprocal Agents, October 2008

2416 Vittorio Daniele and Ugo Marani, Organized Crime and Foreign Direct Investment: The Italian Case, October 2008

2417 Valentina Bosetti, Carlo Carraro, Alessandra Sgobbi and Massimo Tavoni, Modelling Economic Impacts of Alternative International Climate Policy Architectures. A Quantitative and Comparative Assessment of Architectures for Agreement, October 2008

2418 Paul De Grauwe, Animal Spirits and Monetary Policy, October 2008

2419 Guglielmo Maria Caporale, Christophe Rault, Robert Sova and Anamaria Sova, On the Bilateral Trade Effects of Free Trade Agreements between the EU-15 and the CEEC-4 Countries, October 2008

2420 Yin-Wong Cheung and Daniel Friedman, Speculative Attacks: A Laboratory Study in Continuous Time, October 2008

2421 Kamila Fialová and Ondřej Schneider, Labour Market Institutions and their Effect on Labour Market Performance in the New EU Member Countries, October 2008

2422 Alexander Ludwig and Michael Reiter, Sharing Demographic Risk - Who is Afraid of the Baby Bust?, October 2008

2423 Doina Maria Radulescu and Michael Stimmelmayr, The Welfare Loss from Differential Taxation of Sectors in Germany, October 2008

2424 Nikolaus Wolf, Was Germany ever United? Evidence from Intra- and International Trade 1885 - 1933, October 2008

2425 Bruno S. Frey, David A. Savage and Benno Torgler, Noblesse Oblige? Determinants of Survival in a Life and Death Situation, October 2008

2426 Giovanni Facchini, Peri Silva and Gerald Willmann, The Customs Union Issue: Why do we Observe so few of them?, October 2008

2427 Wido Geis, Silke Uebelmesser and Martin Werding, Why go to France or Germany, if you could as well go to the UK or the US? Selective Features of Immigration to four major OECD Countries, October 2008 
2428 Geeta Kingdon and Francis Teal, Teacher Unions, Teacher Pay and Student Performance in India: A Pupil Fixed Effects Approach, October 2008

2429 Andreas Haufler and Marco Runkel, Firms' Financial Choices and Thin Capitalization Rules under Corporate Tax Competition, October 2008

2430 Matz Dahlberg, Heléne Lundqvist and Eva Mörk, Intergovernmental Grants and Bureaucratic Power, October 2008

2431 Alfons J. Weichenrieder and Tina Klautke, Taxes and the Efficiency Costs of Capital Distortions, October 2008

2432 Andreas Knabe and Ronnie Schöb, Minimum Wage Incidence: The Case for Germany, October 2008

2433 Kurt R. Brekke and Odd Rune Straume, Pharmaceutical Patents: Incentives for R\&D or Marketing?, October 2008

2434 Scott Alan Carson, Geography, Insolation, and Institutional Change in $19^{\text {th }}$ Century African-American and White Stature in Southern States, October 2008

2435 Emilia Del Bono and Daniela Vuri, Job Mobility and the Gender Wage Gap in Italy, October 2008

2436 Marco Angrisani, Antonio Guarino, Steffen Huck and Nathan Larson, No-Trade in the Laboratory, October 2008

2437 Josse Delfgaauw and Robert Dur, Managerial Talent, Motivation, and Self-Selection into Public Management, October 2008

2438 Christian Bauer and Wolfgang Buchholz, How Changing Prudence and Risk Aversion Affect Optimal Saving, October 2008

2439 Erich Battistin, Clara Graziano and Bruno Parigi, Connections and Performance in Bankers' Turnover: Better Wed over the Mixen than over the Moor, October 2008

2440 Erkki Koskela and Panu Poutvaara, Flexible Outsourcing and the Impacts of Labour Taxation in European Welfare States, October 2008

2441 Marcelo Resende, Concentration and Market Size: Lower Bound Estimates for the Brazilian Industry, October 2008

2442 Giandomenico Piluso and Roberto Ricciuti, Fiscal Policy and the Banking System in Italy. Have Taxes, Public Spending and Banks been Procyclical in the Long-Run? October 2008

2443 Bruno S. Frey and Katja Rost, Do Rankings Reflect Research Quality?, October 2008

2444 Guglielmo Maria Caporale, Antoaneta Serguieva and Hao Wu, Financial Contagion: Evolutionary Optimisation of a Multinational Agent-Based Model, October 2008 
2445 Valentina Bosetti, Carlo Carraro and Massimo Tavoni, Delayed Participation of Developing Countries to Climate Agreements: Should Action in the EU and US be Postponed?, October 2008

2446 Alexander Kovalenkov and Xavier Vives, Competitive Rational Expectations Equilibria without Apology, November 2008

2447 Thiess Buettner and Fédéric Holm-Hadulla, Cities in Fiscal Equalization, November 2008

2448 Harry H. Kelejian and Ingmar R. Prucha, Specification and Estimation of Spatial Autoregressive Models with Autoregressive and Heteroskedastic Disturbances, November 2008

2449 Jan Bouckaert, Hans Degryse and Thomas Provoost, Enhancing Market Power by Reducing Switching Costs, November 2008

2450 Frank Heinemann, Escaping from a Combination of Liquidity Trap and Credit Crunch, November 2008

2451 Dan Anderberg, Optimal Policy and the Risk Properties of Human Capital Reconsidered, November 2008

2452 Christian Keuschnigg and Evelyn Ribi, Outsourcing, Unemployment and Welfare Policy, November 2008

2453 Bernd Theilen, Market Competition and Lower Tier Incentives, November 2008

2454 Ondřej Schneider, Voting in the European Union - Central Europe's Lost Voice, November 2008

2455 Oliver Lorz and Gerald Willmann, Enlargement versus Deepening: The Trade-off Facing Economic Unions, November 2008

2456 Alfons J. Weichenrieder and Helen Windischbauer, Thin-Capitalization Rules and Company Responses, Experience from German Legislation, November 2008

2457 Andreas Knabe and Steffen Rätzel, Scarring or Scaring? The Psychological Impact of Past Unemployment and Future Unemployment Risk, November 2008

2458 John Whalley and Sean Walsh, Bringing the Copenhagen Global Climate Change Negotiations to Conclusion, November 2008

2459 Daniel Mejía, The War on Illegal Drugs in Producer and Consumer Countries: A Simple Analytical Framework, November 2008 